\title{
The effects of second-generation rent control on land values Online Appendix
}

\author{
Andreas Mense, Claus Michelsen and Konstantin A. Kholodilin
}

January 11, 2019

Table 1: LOGIT MODEL RESUltS

\begin{tabular}{lcc}
\hline \hline Dependent variable: rent cap municipality dummy & Coef. & robust SE \\
\hline unemployed per resident & $-128.22^{* *}$ & $(47.15)$ \\
population density & $66.26^{* * *}$ & $(15.07)$ \\
residential area share & $-41.76^{* * *}$ & $(8.96)$ \\
homeownership rate 2011 & $-14.44^{* * *}$ & $(3.89)$ \\
dummy: homeownership rate NA & $-20.33^{* * *}$ & $(2.61)$ \\
vacancy rate & $-35.66^{* *}$ & $(11.90)$ \\
units per residential building 2011 & -1.71 & $(1.11)$ \\
dummy: units per residential building NA & $-16.75^{* * *}$ & $(2.08)$ \\
land price 2010-2012 & $0.01^{* * *}$ & $(0.00)$ \\
change of land price, (2010-2012) vs. (2013-2014) & $1.49^{* * *}$ & $(0.45)$ \\
\hline Observations & 1515 & \\
Rent cap municipalities & 118 & \\
Other municipalities & 1397 & \\
Sample year & 2011 & \\
Note: Heteroskedasticity-robust standard errors in paretheses. ${ }^{* * *}: \mathrm{p}<.001,{ }^{* *}: \mathrm{p}<.01,{ }^{*}: \mathrm{p}<.05$
\end{tabular}

Table 2: Means of important variables, 2010-2014

\begin{tabular}{lccccc}
\hline \hline & \multicolumn{2}{c}{ Full sample } & & \multirow{2}{*}{ Trimmed sample } \\
\cline { 2 - 3 } \cline { 5 - 6 } Variable & rent cap & other & & rent cap & other \\
\hline land price index & 1.098 & 1.044 & & 1.093 & 1.088 \\
land price per square meter & 445.7 & 110.5 & & 359.9 & 278.5 \\
square meter per sale & 0.984 & 0.910 & & 0.852 & 0.889 \\
unemployed per capita & 0.016 & 0.015 & & 0.016 & 0.014 \\
childcare occupancy rate & 0.915 & 0.875 & & 0.920 & 0.889 \\
business starts per capita & 0.002 & 0.002 & & 0.002 & 0.002 \\
\hline
\end{tabular}

Note: The table refers to the years 2010-2014. Columns "rent cap" refer to rent cap municipalities, columns "other" refer to other/control municipalities. 
Table 3: AdDITIONAL LAND PRICE REGRESSIONS

\begin{tabular}{|c|c|c|c|}
\hline & \multicolumn{3}{|c|}{ Dependent variable } \\
\hline & $\begin{array}{l}\text { Index } \\
(1)\end{array}$ & $\begin{array}{c}\log \text { price } / \mathrm{m}^{2} \\
(2)\end{array}$ & $\begin{array}{c}\text { price } / \mathrm{m}^{2} \\
(3)\end{array}$ \\
\hline $\begin{array}{l}\text { square meter } \\
\text { per sale }\end{array}$ & $\begin{array}{c}-0.18^{* * *} \\
(0.04)\end{array}$ & $\begin{array}{c}-0.18^{* * *} \\
(0.03)\end{array}$ & $\begin{array}{c}-43.85^{* * *} \\
(9.38)\end{array}$ \\
\hline $\begin{array}{l}\text { business starts } \\
\text { per capita }\end{array}$ & $\begin{array}{l}-2.46 \\
(6.20)\end{array}$ & & \\
\hline $\begin{array}{c}\text { childcare occu- } \\
\text { pancy rate }\end{array}$ & $\begin{array}{l}-0.61^{*} \\
(0.26)\end{array}$ & & \\
\hline $\begin{array}{l}\text { unemployed } \\
\text { per capita }\end{array}$ & $\begin{array}{l}-8.14 \\
(7.72)\end{array}$ & & \\
\hline year 2015 & $\begin{array}{c}0.20^{* * *} \\
(0.06)\end{array}$ & $\begin{array}{c}0.18^{* * *} \\
(0.04)\end{array}$ & $\begin{array}{c}57.32^{* * *} \\
(15.03)\end{array}$ \\
\hline year 2016 & $\begin{array}{c}0.39^{* * *} \\
(0.06)\end{array}$ & $\begin{array}{c}0.30^{* * *} \\
(0.04)\end{array}$ & $\begin{array}{c}104.19^{* * *} \\
(17.95)\end{array}$ \\
\hline $\begin{array}{l}\text { rent cap } \times \\
\text { year } 2015\end{array}$ & $\begin{array}{c}0.10 \\
(0.08)\end{array}$ & $\begin{array}{c}0.08 \\
(0.06)\end{array}$ & $\begin{array}{l}45.19 \\
(26.50)\end{array}$ \\
\hline $\begin{array}{r}\text { rent cap } \times \\
\text { year } 2016 \\
\end{array}$ & $\begin{array}{l}0.21^{*} \\
(0.09)\end{array}$ & $\begin{array}{c}0.12 \\
(0.06)\end{array}$ & $\begin{array}{l}92.57^{* *} \\
(33.55) \\
\end{array}$ \\
\hline Trimmed & yes & yes & yes \\
\hline Weighted & yes & yes & yes \\
\hline Observations & 693 & 701 & 701 \\
\hline Treated units & 64 & 64 & 64 \\
\hline Control units & 103 & 103 & 103 \\
\hline
\end{tabular}

Note: Standard errors (in parentheses) clustered at the municipality level; ${ }^{* * *}: \mathrm{p}<.001,{ }^{* *}: \mathrm{p}<.01,{ }^{*}: \mathrm{p}<.05$. 